\title{
Optimasi perencanaan produksi bahan bakar minyak dengan fungsi kendala fuzzy menggunakan metode goal programming
}

\author{
Wiwiet Widyaningsih *, Sri Andayani \\ Jurusan Pendidikan Matematika, Universitas Negeri Yogyakarta. \\ Jalan Colombo No. 1, Karangmalang, Yogyakarta 55281, Indonesia. \\ * Corresponding Author. E-mail: wiwietwidyaningsih27@gmail.com \\ Received: 11 June 2018; Revised: 17 September 2018; Accepted: 21 September 2018
}

\begin{abstract}
Abstrak
Dalam perencanaan produksi PT. Pertamina (Persero) TBBM Boyolali, perusahaan tersebut hanya mendistribusikan BBM sesuai dengan permintaan SPBU tanpa melakukan perhitungan matematis apakah pendapatan yang diperoleh sudah optimal dengan semua faktor dan kendala yang ada, seperti harga setiap jenis BBM, jam kerja mesin pengisian BBM di New Gantry System (NGS), moda transport mobil tangki, dan tingkat keselamatan mobil tangki. Untuk itu, penelitian ini bertujuan untuk melakukan optimasi perencanaan produksi BBM menggunakan metode goal programming agar perusahaan dapat memperoleh pendapatan yang maksimal dengan memperhatikan faktor-faktor dan kendala yang ada. Metode goal programming merupakan perluasan dari linear programming yang dapat menyelesaikan optimasi dengan banyak tujuan. Pada penelitian ini, selain dengan fungsi kendala biasa, metode goal programming juga digunakan untuk menyelesaikan permasalahan yang sama ditambah dengan satu fungsi kendala fuzzy, yaitu tingkat keselamatan mobil tangki, yang proses defuzzifikasinya menggunakan metode mamdani. Hasil penelitian menunjukkan, kedua penyelesaian metode goal programming baik dengan kendala biasa maupun dengan kendala fuzzy memberikan keluaran jumlah BBM dan jumlah pendapatan yang sama, yaitu produk premium $\left(X_{1}\right)$ sebanyak $1016 \mathrm{kl}$, bio solar $\left(X_{2}\right)$ sebanyak $1200 \mathrm{kl}$, pertamax $\left(X_{3}\right)$ sebanyak $596 \mathrm{kl}$, dan pertalite $\left(X_{4}\right)$ sebanyak $1632 \mathrm{kl}$ dengan pendapatan sebesar Rp33.022.000.000,00.
\end{abstract}

Kata Kunci: optimasi, perencanaan produksi, goal programming, fuzzy

\section{Optimization planning of fuel oil production with fuzzy constraint using goal programming method}

\begin{abstract}
In the production planning of PT. Pertamina (Persero) TBBM Boyolali, it only distributes fuel in accordance with the demand for gas stations without performing mathematical calculations whether the revenue obtained was optimal with all the factors and obstacles that exist, such as the price of each type of fuel, working hours of filling machine fuel in New Gantry System (NGS), transport modes of the tank car, and the tank car's safety level. Therefore, this study aims to optimize the production planning using goal programming method so that the company can obtain maximum income by considering the factors and constraints. The goal programming method was an extension of linear programming that can accomplish optimization with many goals. In this study, in addition to the ordinary constraint function, goal programming method was also used to solve the same problem which includes one fuzzy constraint, namely the level of tank car safety, which the defuzzification process using Mamdani method. The result of the study shows that solution of goal programming method both with ordinary and fuzzy constraint give the same amount of fuel output and the same amount of revenue, that is premium $\left(X_{1}\right)$ as much $1016 \mathrm{kl}$, bio diesel $\left(X_{2}\right)$ as much $1200 \mathrm{kl}$, pertamax $\left(X_{3}\right)$ as much $596 \mathrm{kl}$ and pertalite $\left(X_{4}\right)$ as much 1632 $\mathrm{kl}$ with the revenue is $R$ p33.022.000.000,00.
\end{abstract}

Keywords: optimization, production planning, goal programming, fuzzy

How to Cite: Widyaningsih, W., \& Andayani, S. (2018). Optimasi perencanaan produksi bahan bakar minyak dengan fungsi kendala fuzzy menggunakan metode goal programming. Pythagoras: Jurnal Pendidikan Matematika, 13(1), 21-32. doi:http://dx.doi.org/10.21831/pg.v13i1.19995

doi) http://dx.doi.org/10.21831/pg.v13i1.19995 


\section{PENDAHULUAN}

Matematika merupakan ilmu eksak atau ilmu pasti yang memiliki peran yang sangat vital dalam kehidupan sehari-hari. Salah satu contoh penerapannya adalah dalam penyelesaian masalah optimasi. Optimasi merupakan pencapaian suatu keadaan yang terbaik, yaitu pencapaian suatu solusi masalah yang diarahkan pada batas maksimum dan minimum (Soekartawi, 1992). Optimasi dapat diselesaikan dengan metode linear programming, yang dibagi kedalam dua jenis fungsi tujuan, yaitu satu fungsi tujuan (single goal) dan lebih dari satu fungsi tujuan atau multi tujuan (multi goal/multiobjektif).

Goal programming merupakan salah satu metode dalam optimasi multiobjektif. Goal programming adalah salah satu model matematis yang dipandang sesuai digunakan untuk pemecahan masalah multi tujuan, karena melalui variabel deviasionalnya, goal programming secara otomatis menangkap informasi tentang pencapaian relatif dari tujuan yang ada (Charles \& Simpson, 2002). Penyelesaian goal programming adalah dengan cara mengubah beberapa tujuan tersebut menjadi satu tujuan (single goal). Perbedaannya dengan linear programming single goal hanya terletak pada kehadiran sepasang variabel deviasional yang muncul pada fungsi tujuan dan fungsi-fungsi kendala (Siswanto, 2007). Optimasi dengan metode goal programming ini dapat diaplikasikan dalam optimasi perencanaan produksi di perusahaan. Salah satunya adalah di PT. Pertamina (Persero) TBBM Boyolali. Perencanaan produksi didefinisikan sebagai proses untuk memproduksi barang-barang pada suatu periode tertentu sesuai dengan yang diramalkan atau dijadwalkan melalui pengorganisasian sumber daya. Tujuan perencanaan produksi yaitu menyusun suatu rencana produksi untuk memenuhi permintaan pada waktu yang tepat dengan menggunakan sumber-sumber yang tersisa dengan biaya yang paling minimum dari keseluruhan produk (Baroto, 2002).

Perencanaan produksi di PT. Pertamina (Persero) TBBM Boyolali adalah perencanaan jumlah BBM yang akan didistribusikan ke SPBU-SPBU tujuan yang meliputi 4 jenis BBM (premium, bio solar, pertamax, pertalite) dalam waktu 1 hari agar PT. Pertamina mendapatkan keuntungan yang maksimal. Selama ini PT. Pertamina (Persero) TBBM Boyolali hanya mendistribusikan BBM sesuai dengan permintaan SPBU tanpa melakukan perhitungan matematis apakah pendapatan yang diperoleh sudah optimal dengan semua faktor dan kendala yang ada, seperti harga setiap jenis BBM, jam kerja mesin pengisian BBM di NGS, moda transport (alat angkut) mobil tangki, dan tingkat keselamatan mobil tangki yang dipengaruhi oleh kedalaman tapak ban dan jarak SPBU. Untuk itu, PT. Pertamina (Persero) TBBM Boyolali perlu melakukan optimasi perencanaan produksi BBM agar dapat memenuhi sasaran memaksimalkan volume produksi untuk memenuhi jumlah permintaan, memaksimalkan pendapatan penjualan, memaksimalkan jam kerja mesin pengisian BBM di NGS, memaksimalkan moda transport mobil tangki, serta memaksimalkan tingkat keselamatan mobil tangki dalam mendistribusikan BBM melalui faktor kedalaman tapak ban mobil tangki dan jarak SPBU.

Optimasi perencanaan produksi ini akan menggunakan metode goal programming dengan tambahan kendala fuzzy pada sasaran memaksimalkan tingkat keselamatan mobil tangki dalam mendistribusikan BBM, karena logika fuzzy memiliki kelebihan sendiri yaitu kemampuannya dalam proses penalaran secara bahasa (linguistik), dalam perancangannya tidak memerlukan persamaan matematika yang rumit, mudah dimengerti dan memiliki toleransi terhadap data-data yang tidak tepat. Fuzzy merupakan suatu nilai yang dapat bernilai benar atau salah secara bersamaan. Namun seberapa besar nilai kebenaran dan kesalahannya tergantung pada derajat keanggotaan yang dimilikinya. Derajat keanggotaan dalam fuzzy memiliki rentang nilai 0 (nol) hingga 1 (satu), yang dapat direpresentasikan dalam bentuk kurva, seperti kurva linier naik, linier turun, segitiga dan trapesium. (Setiadji, 2009; Kusumadewi \& Idham, 2005).

Berdasarkan uraian tersebut, maka penelitian ini bertujuan untuk melakukan optimasi perencanaan produksi BBM menggunakan metode goal programming agar perusahaan dapat memperoleh pendapatan yang maksimal dengan memperhatikan faktor-faktor dan kendala yang ada. Metode goal programming merupakan perluasan dari linear programming yang dapat menyelesaikan optimasi dengan banyak tujuan.

\section{METODE}

Penelitian ini bertujuan untuk mengoptimasi perencanaan produksi BBM di PT. Pertamina (Persero) TBBM Boyolali. Langkah-langkah yang ditempuh untuk mencapai tujuan tersebut meliputi pengumpulan sumber data, definisi operasional variabel dan teknik analasis data. 


\section{Sumber Data}

Data yang digunakan dalam penelitian ini merupakan data sekunder dari PT. Pertamina (Persero) TBBM Boyolali yang beralamat di Jl. Solo Semarang KM 18 Kecamatan Teras Kabupaten Boyolali Provinsi Jawa Tengah yang diambil pada tanggal 4 Februari 2017. Data yang dibutuhkan dalam penyelesaian masalah adalah data harga jual tiap jenis BBM, data estimasi permintaan, data jam kerja mesin pengisian BBM di NGS, data jumlah flowrate tiap jenis BBM di NGS, data jumlah arm (lengan/selang pengisian) dan bay (teluk/area masuk) di NGS, data jumlah mobil tangki, data kedalaman tapak ban mobil tangki dan data jarak SPBU.

\section{Definisi Operasional Variabel}

Permasalahan-permasalahan dalam penelitian akan diselesaikan menggunakan metode goal programming. Penyelesaian tersebut melibatkan beberapa variabel. Definisi operasional dari variabel-variabel tersebut adalah sebagai berikut.

Jumlah produk $\boldsymbol{j}$ yang diproduksi $\left(X_{j}\right)$, yaitu jumlah masing-masing volume produk BBM (premium, bio solar, pertamax dan pertalie) yang diproduksi per hari untuk memenuhi permintaan BBM dalam satuan per kiloliter, dengan $j=1,2$, 3,4 .

Jumlah permintaan terhadap produk $\boldsymbol{j}$ pada kendala ke-i $\left(\boldsymbol{P}_{\boldsymbol{i} \boldsymbol{j}}\right)$, yaitu jumlah permintaan masing-masing jenis BBM dari SPBU-SPBU tujuan per hari dalam satuan per kiloliter, dengan $j=1$, $2,3,4$ dan $i=1,2, \ldots, m$.

Harga jual per unit produk $\boldsymbol{j}\left(\boldsymbol{H}_{\boldsymbol{j}}\right)$, yaitu harga jual setiap jenis BBM dari PT. Pertamina (Persero) TBBM Boyolali ke SPBU-SPBU tujuan per kiloliter dalam satuan rupiah, dengan $j=1,2,3$, 4.

Pendapatan penjualan pada kendala ke- $i\left(F_{i}\right)$, yaitu total pendapatan yang diperoleh PT. Pertamina (Persero) TBBM Boyolali dari hasil penjualan BBM ke SPBU-SPBU tujuan per hari dalam satuan rupiah, dengan $i=1,2, \ldots, m$.

Kapasitas jam kerja mesin pengisisan BBM di NGS pada kendala ke- $\boldsymbol{I}\left(\boldsymbol{W}_{\boldsymbol{i}}\right)$, yaitu total lamanya waktu pengoperasian mesin pengisian BBM di NGS yang didapat dari hasil perkalian antara banyaknya jumlah arm dalam filling point (titik pengisian) dengan lamanya arm bekerja dalam satu hari dalam satuan menit, dengan $i=1,2, \ldots$, $m$.

Waktu pengisian BBM jenis $\boldsymbol{j}$ ke kompartemen (bagian) mobil tangki $\left(w_{j}\right)$, yaitu lamanya waktu mengalirkan BBM dari arm ke dalam kompartemen (mobil tangki per 1 kiloliter dalam satuan menit, dengan $j=1,2,3,4$.

Total kapasitas mobil tangki pada kendala ke$\boldsymbol{i}\left(\boldsymbol{M}_{\boldsymbol{i}}\right)$, yaitu total penjumlahan kapasitas 91 mobil tangki dalam satuan kiloliter, dengan $i=1$, $2, \ldots, m$.

Nilai rata-rata defuzzifikasi pasangan kedalaman tapak ban mobil tangki dan jarak spbu untuk produk $j$ pada zona ke- $k\left(c_{j k}\right)$, yaitu nilai rata-rata dari nilai defuzzifikasi pasangan kedalaman tapak ban mobil tangki dan jarak spbu disetiap zona (zona 1, zona 2 dan zona 3 ), dengan $j=1,2,3,4$ dan $k=1,2,3$.

Total jumlah permintaan BBM di zona ke- $k$ pada kendala ke- $\boldsymbol{I}\left(\boldsymbol{B}_{\boldsymbol{i} \boldsymbol{k}}\right)$, yaitu jumlah permintaan BBM dari SPBU-SPBU tujuan dimasingmasing zona per hari dalam satuan per kiloliter, dengan $i=1,2, \ldots, m$ dan $k=1,2,3$.

Permasalahan goal programming dalam penelitian ini mempunyai 4 variabel keputusan, yaitu sebagai berikut: (1) $X_{1}=$ Jumlah premium yang disediakan (kilo liter) dalam 1 hari; (2) $X_{2}=$ Jumlah bio solar yang disediakan (kiloliter) dalam 1 hari; (3) $X_{3}=$ Jumlah pertamax yang disediakan (kiloliter) dalam 1 hari; (4) $X_{4}=$ Jumlah pertalite yang disediakan (kiloliter) dalam 1 hari.

\section{Teknik Analisis Data}

Dalam tahap ini dilakukan proses optimasi model matematika dengan fungsi kendala biasa dan fungsi kendala fuzzy menggunakan metode goal programming dengan program LINGO. Tahapan-tahapan optimasi perencanaan produksi pada penelitian ini dijelaskan dalam Gambar 1.

\section{HASIL DAN PEMBAHASAN}

Solusi terhadap permasalahan optimasi perencanaan produksi di PT. Pertamina (Persero) TBBM Boyolali akan dibahas menjadi 3 bagian, yaitu optimasi menggunakan goal programming dengan fungsi kendala biasa, optimasi menggunakan goal programming dengan fungsi kendala fuzzy tingkat keselamatan mobil tangki yang ditentukan oleh data kedalaman tapak ban mobil tangki dan jarak ke lokasi SPBU tujuan, dan pembahasan terhadap hasilnya.

PT. Pertamina (Persero) TBBM Boyolali menjual empat jenis BBM ke SPBU-SPBU, yaitu premium, bio solar, pertamax dan pertalite dengan harga jual yang berbeda-beda. Dalam menjalankan tugasnya, PT. Pertamina TBBM Boyolali diharuskan dapat memenuhi setiap jumlah permintaan BBM dari SPBU-SPBU tujuan setiap hari. Harga jual dan total permintaan setiap jenis BBM per hari disajikan dalam Tabel 1. 
Pythagoras, 13 (1), 2018 - 24

Wiwiet Widyaningsih, Sri Andayani

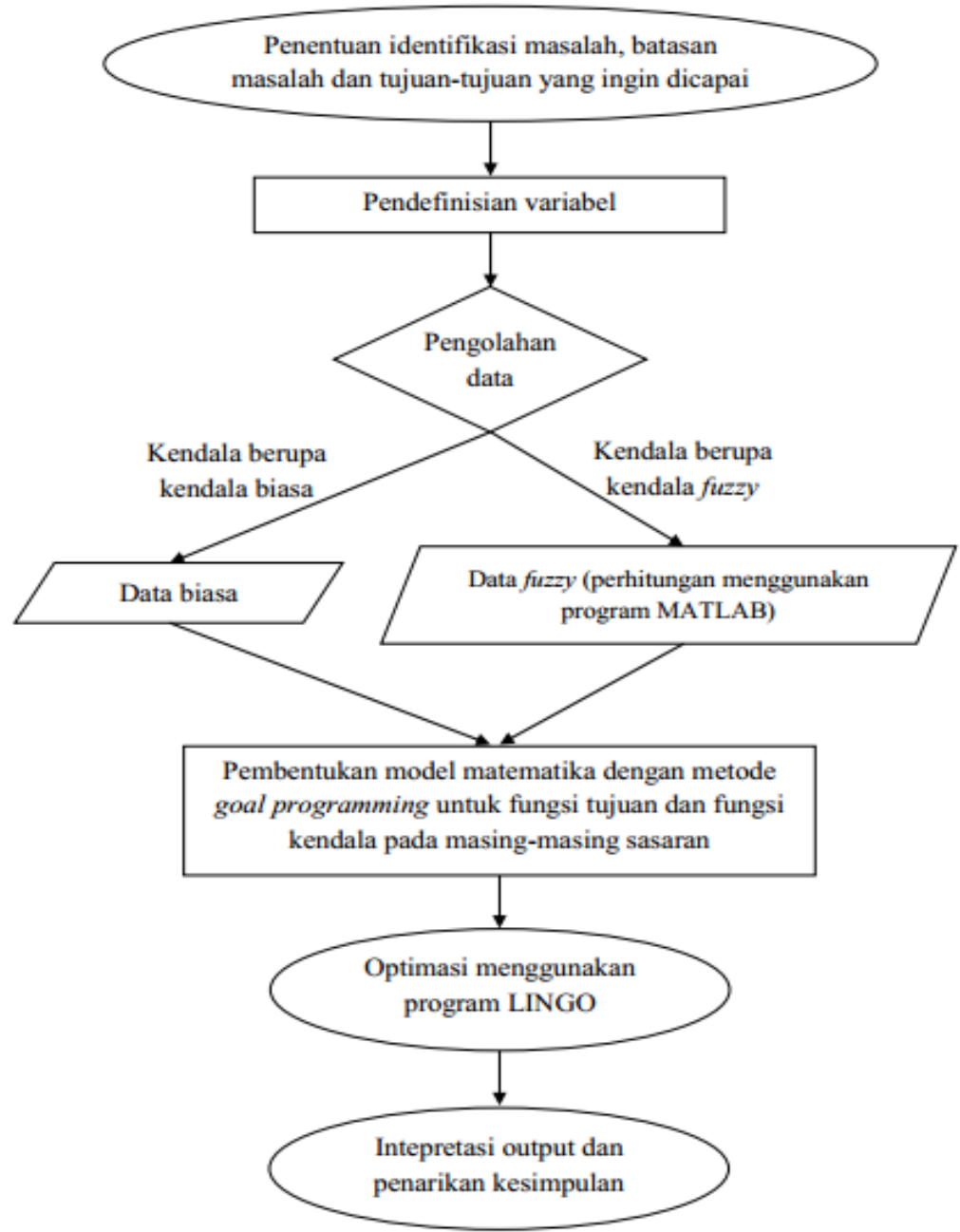

Gambar 1. Flowchart Penelitian

PT. Pertamina (Persero) TBBM Boyolali merupakan lokasi ke delapan dalam pengoperasian New Gantry System (NGS) sebagai mesin pengisian BBM ke dalam kompartemen mobil tangki dengan flowrate sekitar 2000 liter/menit. Di dalam NGS, terdapat 4 bay sebagai tempat masuk atau area mobil tangki untuk mengisikan BBM ke dalam kompartemen mobil tangki (TBBM Boyolali terapkan new gantry system, 2017). Masing-masing bay memiliki jenis arm yang berbeda-beda, sehingga waktu yang dibutuhkan untuk mengisikan BBM ke kompartemen mobil tangki (MT) per 1 kiloliter juga berbedabeda, yaitu premium selama 0.125 menit, bio solar selama 0.167 menit pertamax selama 0.125 menit dan pertalite selama 0.167 menit. Setiap arm dapat bekerja selama 720 menit per hari sehingga total kapasitas jam kerja mesin pengisian BBM berdasarkan banyaknya arm adalah selama 10080 menit per hari.

Operasi pendistribusian BBM di PT. Pertamina (Persero) TBBM Boyolali menggunakan moda transport mobil tangki. Total kapasitas seluruh mobil tangki yang digunakan untuk mendistribusikan BBM adalah sebesar 2144 kl. Dalam pengoperasian mobil tangki, ban memiliki pengaruh yang besar sebagai standar apakah mobil tangki tersebut layak untuk beroperasi atau tidak. Standar kelayakan ban mobil tangki ini diukur dari kedalaman tapak ban. Ban mobil tangki yang baru memiliki kedalaman tapak ban sekitar 7 milimeter $(\mathrm{mm})$ dan $8 \mathrm{~mm}$, sedangkan batas kelayakan tapak ban sekitar 1,6 mm. Ban dengan kedalaman tapak dibawah 1,6 mm sudah tidak layak digunakan karena sudah terlalu halus dan licin yang dapat menimbulkan bahaya kecelakaan karena tergelincir, sehingga harus diganti dengan ban yang baru. Dalam pendistribusian BBM ke SPBU-SPBU tujuan, PT. Pertamina (Persero) TBBM Boyolali menggunakan pola distribusi dengan sistem zonasi karena dianggap sebagai sistem yang paling optimal dalam pendistribusian BBM. Sistem zonasi ini dibagi ke dalam 3 zona, yaitu zona 1 untuk SPBU yang berada di wilayah 0 sampai 30 kilometer $(\mathrm{km})$ dari 
PT. Pertamina, zona 2 di wilayah 31 sampai 60 $\mathrm{km}$ dan zona 3 di wilayah 61 sampai $185 \mathrm{~km}$. Jumlah total permintaan BBM dari SPBU-SPBU disetiap zona juga berbeda-beda. Jumlah permintaan BBM pada zona 1 sebanyak $1820 \mathrm{kl}$, zona 2 sebanyak $1552 \mathrm{kl}$ dan zona 3 sebanyak $1072 \mathrm{kl}$.

Jumlah SPBU tujuan pendistribusian BBM di PT. Pertamina (Persero) TBBM Boyolali adalah sebanyak 238 SPBU, sedangkan jumlah mobil tangki hanya 91 buah. Hal ini menyebabkan pengiriman dilakukan dengan menggunakan sistem giliran (shift), yaitu satu buah mobil tangki dalam 1 hari mendistribusikan BBM ke lebih dari satu SPBU. Jika mobil tangki mendistribusikan BBM ke SPBU yang pertama kali didatangi, maka dinamakan shift satu. Jika mobil tangki mendistribusikan BBM ke SPBU yang kedua kali didatangi, maka dinamakan shift dua, dan seterusnya.

Tabel 1. Harga jual dan total permintaan setiap jenis BBM

\begin{tabular}{cccc}
\hline Jenis & $\begin{array}{c}\text { Harga } \\
\text { per } \\
\text { iter } \\
\text { BBM }\end{array}$ & $\begin{array}{c}\text { Harga } \\
\text { per } \\
\text { kiloliter } \\
(\mathbf{k l})(\mathbf{R p})\end{array}$ & $\begin{array}{c}\text { Total } \\
\text { Permintan } \\
(\mathbf{1} \text { hari/kl) }\end{array}$ \\
\hline Premium & 6600 & 6600000 & 1016 \\
Bio solar & 7200 & 7200000 & 1200 \\
Pertamax & 8300 & 8300000 & 596 \\
Pertalite & 7800 & 7800000 & 1632 \\
\hline
\end{tabular}

Optimasi Menggunakan Goal Programming dengan Fungsi Kendala Biasa

Optimasi perencanaan produksi dalam penelitian ini menggunakan goal programming karena mampu menangani kasus optimasi dengan banyak tujuan. Di dalam goal programming, permasalahan nyata dimodelkan ke dalam bentuk matematika melalui sasaran-sasaran yang berisi tujuan dan kendala-kendala yang dihadapi, dengan formulasi model matematika sebagai berikut (Lestari, Ratna, \& Rosita, 2012).

Formulasi Model Matematika untuk Sasaran

Dalam optimasi perencanaan produksi ini ada 4 sasaran yang ingin dicapai, dengan formulasi model matematika. Sasaran pertama, memaksimalkan volume produksi untuk memenuhi jumlah permintaan. Fungsi kendala untuk sasaran pertama adalah sebagai berikut.

$X_{j}+D B_{i P_{i j}}-D A_{i\left(P_{i j)}\right.}=P_{i j}$

Dimana $X_{j}=$ jumlah produk $j$ yang diproduksi $(j$ $=1,2,3,4) ; P_{i j}=$ jumlah permintaan terhadap produk $j$ pada kendala ke- $i(i=1,2, \ldots, m)$,
$D B_{i\left(P_{i j}\right)}=$ nilai penyimpangan di bawah $P_{i j}$; $D A_{i\left(P_{i j}\right)}=$ nilai penyimpangan di atas $P_{i j}$. Agar jumlah permintaan produk BBM terpenuhi, tidak kurang dan tidak lebih, maka fungsi tujuan $Z_{1}$ adalah sebagai berikut.

$\operatorname{Min} Z_{1}=\sum_{i=1}^{m}\left(D B_{i\left(P_{i j}\right)}+D A_{i\left(P_{i j}\right)}\right)$

Sehingga, model matematika untuk memenuhi jumlah permintaan premium, bio solar, pertamax, dan pertalite berturut-turut adalah sebagai berikut.

$X_{1}+D B_{1}-D A_{1}=1016$

$X_{2}+D B_{2}-D A_{2}=1200$

$X_{3}+D B_{3}-D A_{3}=596$

$X_{4}+D B_{4}-D A_{4}=1632$

Dengan nilai ruas kanan merupakan jumlah permintaan premium, bio solar, pertamax, dan pertalite. Adapun fungsi tujuannya yaitu:

$\operatorname{Min} Z_{1}=D B_{1}+D A_{1}+D B_{2}+D A_{2}+D B_{3}+$ $D A_{3}+D B_{4}+D A_{4}$

Sasaran kedua, memaksimalkan pendapatan penjualan. Fungsi kendala untuk sasaran kedua adalah sebagai berikut.

$\left(\sum_{j=1}^{4} H_{j} X_{j}\right)+D B_{i\left(F_{i}\right)}=F_{i}$

Dimana, $H_{j}=$ harga jual per unit produk $j(j=1$, $2,3,4) ; X_{j}=$ jumlah produk $j$ yang diproduksi; $F_{i}$ $=$ pendapatan penjualan pada kendala ke- $i(i=1$, $2, \ldots, m) ; D B_{i\left(F_{i}\right)}=$ nilai penyimpangan di bawah $F_{i}$.

Agar pendapatan penjualan maksimal, maka fungsi tujuan $Z_{2}$ menjadi:

$\operatorname{Min} Z_{2}=\sum_{i=1}^{m} D B_{i\left(F_{i}\right)}$

Sehingga, model matematika untuk memaksimalkan pendapatan penjualan adalah sebagai berikut:

$$
\begin{aligned}
& 6600000 X_{1}+7200000 X_{2}+8300000 X_{3}+ \\
& 7800000 X_{4}+D B_{5}=F
\end{aligned}
$$

Dengan nilai ruas kanan merupakan pendapatan yang ingin dicapai dan nilai koefisien pada setiap variabel di ruas kiri adalah harga masing-masing jenis BBM. Adapun fungsi tujuannya yaitu:

$\operatorname{Min} Z_{2}=D B_{5}$

Sasaran ketiga, memaksimalkan jam kerja mesin pengisian BBM di NGS. Fungsi kendala untuk sasaran ketiga sebagai berikut. 


$$
\left(\sum_{j=1}^{4} w_{j} X_{j}\right)+D B_{i\left(W_{i}\right)}-D A_{i\left(W_{i}\right)}=W_{i}
$$

Dimana, $X_{j}=$ jumlah produk $j$ yang diproduksi $(j=1,2,3,4) ; W_{i}=$ kapasitas jam kerja mesin pengisisan BBM di NGS pada kendala ke$i(i=1,2, \ldots, m) ; w_{j}=$ waktu pengisian $\mathrm{BBM}$ jenis $j$ ke kompatermen MT; $D B_{i\left(W_{i}\right)}=$ nilai penyimpangan di bawah $W_{i} ; D A_{i\left(W_{i}\right)}=$ nilai penyimpangan di atas $W_{i}$. Agar jam kerja mesin pengisian BBM di NGS maksimal, maka fungsi tujuan $Z_{3}$ menjadi:

$\operatorname{Min} Z_{3}=\sum_{i=1}^{m}\left(D B_{i\left(W_{i}\right)}+D A_{i\left(W_{i}\right)}\right)$

Sehingga, model matematika untuk memaksimalkan jam kerja mesin pengisian BBM di NGS adalah sebagai berikut:

$0,125 X_{1}+0,167 X_{2}+0,125 X_{3}+0,167 X_{4}+$

$D B_{6}-D A_{6}=10080$

Dengan nilai ruas kanan merupakan total jam kerja mesin pengisian BBM di NGS dan nilai koefisien pada setiap variabel di ruas kiri adalah waktu pengisian setiap jenis BBM ke kompatermen mobil tangki. Adapun fungsi tujuannya yaitu:

$\operatorname{Min} Z_{3}=D B_{6}+D A_{6}$

Sasaran keempat, memaksimalkan moda transport mobil tangki. Fungsi kendala untuk sasaran keempat sebagai berikut.

$$
\left(\sum_{j=1}^{4} X_{j}\right)+D B_{i\left(M_{i}\right)}-D A_{i\left(M_{i}\right)}=M_{i}
$$

Dimana $X_{j}=$ jumlah produk $j$ yang diproduksi $(j$ $=1,2,3,4) ; M_{i}=$ total kapasitas mobil tangki pada kendala ke- $i(i=1,2, \ldots, m) ; D B_{i\left(M_{i}\right)}=$ nilai penyimpangan di bawah $M_{i} ; D A_{i\left(M_{i}\right)}=$ nilai penyimpangan di atas $M_{i}$. Agar jam kerja mesin pengisian BBM di NGS maksimal, maka fungsi tujuan $Z_{4}$ menjadi:

$\operatorname{Min} Z_{4}=\sum_{i=1}^{m} D B_{i\left(M_{i}\right)}$

Sehingga, model matematika untuk memaksimalkan moda transport mobil tangki adalah sebagai berikut:

$X_{1}+X_{2}+X_{3}+X_{4}+D B_{7}-D A_{7}=2144$ (10) Dengan ruas kiri merupakan BBM yang akan diangkut dan didistribusikan oleh mobil tangki dan nilai ruas kanan merupakan total kapasitas mobil tangki. Adapun fungsi tujuannya yaitu:

$\operatorname{Min} Z_{4}=D B_{7}$

Penyelesaian Optimasi Menggunakan Program LINGO

Penyelesaian optimasi dilakukan menggunakan program LINGO dengan memasukkan script input berupa fungsi tujuan dan fungsi kendala yang sudah dibentuk kemudian menggunakan perintah "Solve" untuk mengoptimasikannya. Hasil optimasi yang dilakukan dengan program LINGO untuk metode goal programming dengan fungsi kendala biasa dapat dilihat pada Tabel 2.

Berdasarkan hasil optimasi goal programming dengan fungsi kendala biasa menggunakan program LINGO pada Tabel 2, didapat hasil intepretasi sebagai berikut: (1) sasaran memaksimalkan volume produksi untuk memenuhi jumlah permintaan tercapai. Sasaran yang diinginkan adalah $X_{1}$ sebesar $1016, X_{2}$ sebesar $1200, X_{3}$ sebesar 596 dan $X_{4}$ sebesar 1632, dan hasil yang didapatkan di output sama dengan jumlah sasaran yang diinginkan. Hal ini berati didapatkan nilai premium $\left(X_{1}\right)$ sebanyak $1016 \mathrm{kl}$, bio solar $\left(X_{2}\right)$ sebanyak $1200 \mathrm{kl}$, pertamax $\left(X_{3}\right)$ sebesar $596 \mathrm{kl}$, dan pertalite $\left(X_{4}\right)$ sebanyak $1632 \mathrm{kl}$; (2) sasaran memaksimalkan pendapatan penjualan untuk keempat jenis BBM tersebut per hari dicapai dengan pendapatan sebesar Rp33.022.000.000, 00; (3) sasaran memaksimalkan jam kerja mesin pengisian BBM di NGS tercapai. Sasaran yang diinginkan adalah mesin pengisian BBM di NGS bekerja selama 10080 menit, sedangkan hasil output didapatkan lama mesin pengisian BBM bekerja untuk memenuhi seluruh permintaan hanya selama 674,444 menit. Dari output tersebut juga diketahui bahwa nilai $D A$ adalah sebesar 9405,556 yang artinya mesin menganggur selama 9405,556 menit; (4) sasaran memaksimalkan moda transport mobil tangki tercapai. Sasaran yang diinginkan adalah seluruh mobil tangki dengan kapasitas total sebesar $2144 \mathrm{kl}$ terpakai semua. Didapat nilai $D A$ sebesar 2300, yang artinya masih dibutuhkan mobil tangki dengan kapasitas total sebesar $2300 \mathrm{kl}$ lagi untuk mendistribusikan BBM ke SPBU tujuan, sehingga hal tersebut menunjukkan adanya tiga shift pengiriman, yaitu satu mobil tangki memungkinkan mengantarkan BBM ke tiga SPBU dalam satu hari. 
Pythagoras, 13 (1), 2018 - 27

Wiwiet Widyaningsih, Sri Andayani

Tabel 2. Hasil optimasi goal programming dengan fungsi kendala biasa menggunakan program LINGO

\begin{tabular}{|c|c|c|c|c|c|}
\hline No. & Kendala & Sasaran & $D A$ & $D B$ & Hasil \\
\hline \multirow[t]{4}{*}{1.} & Memaksimalkan volume produksi untuk memenuhi & $\begin{array}{ll}X_{1} & 1016\end{array}$ & 0 & 0 & 1016 \\
\hline & jumlah permintaan & $X_{2} \quad 1200$ & 0 & 0 & 1200 \\
\hline & & 596 & 0 & 0 & 596 \\
\hline & & $X_{4} \quad 1632$ & 0 & 0 & 1632 \\
\hline \multirow{2}{*}{$\begin{array}{l}2 . \\
3 .\end{array}$} & Memaksimalkan pendapatan penjualan & $F$ & 0 & 0 & 33022000000 \\
\hline & $\begin{array}{l}\text { Memaksimalkan jam kerja mesin pengisian BBM di } \\
\text { NGS }\end{array}$ & 10080 & 9405,556 & 0 & 674,444 \\
\hline 4. & Memaksimalkan moda transport mobil tangki & 2144 & 0 & 2300 & 4444 \\
\hline
\end{tabular}

\section{Optimasi Menggunakan Goal Programming dengan Fungsi Kendala Fuzzy Tingkat Keselamatan Mobil Tangki}

Dalam optimasi perencanaan produksi, merupakan hal yang penting untuk memperhatikan fungsi kendala fuzzy tingkat keselamatan mobil tangki yang dipengaruhi oleh kedalaman tapak ban mobil tangki dan jarak SPBU yang ditempuh. Oleh sebab itu, goal programming dalam optimasi perencanaan produksi BBM di PT. Pertamina (Persero) TBBM Boyolali akan dikembangkan dengan menggunakan tambahan fungsi kendala fuzzy tingkat keselamatan mobil tangki yang bergantung pada data kedalaman tapak ban mobil tangki dan jarak SPBU.

Perhitungan Nilai Defuzzifikasi Kedalaman Tapak Ban Mobil Tangki dan jarak SPBU

Terlebih dahulu, data kedalaman tapak ban mobil tangki dan jarak SPBU diurutkan dari yang paling kecil sampai yang paling besar sehingga data kedalaman tapak ban mobil tangki dengan nilai terkecil akan berpasangan dengan data jarak SPBU dengan nilai terkecil pula, dan seterusnya sampai berjumlah 91 pasangan data sesuai dengan banyaknya mobil tangki yang dimiliki PT. Pertamina (Persero) TBBM Boyolali. Sistem pengurutan data dalam pasangan ini bertujuan agar mobil tangki dengan nilai kedalaman tapak ban terkecil akan mendistribusikan BBM ke SPBU dengan jarak terkecil pula, mobil tangki dengan nilai kedalaman tapak ban terbesar akan mendistribusikan BBM ke SPBU dengan jarak terjauh, dan seterusnya. Hal ini didasarkan atas asumsi bahwa kedalaman tapak ban yang kecil memiliki tingkat keselamatan lebih rendah sehingga dipasangkan dengan SPBU dengan jarak terdekat. Hasil akhir dari perhitungan tingkat keselamatan mobil tangki ini akan dibagi per zona, yaitu zona 1 dengan nilai defuzzifikasi 0 sampai 0,3 , zona 2 dengan nilai 0,31 sampai 0,6 dan zona 3 dengan nilai 0,61 sampai 1 .
Dalam perhitungan tingkat keselamatan, aplikasi logika fuzzy melakukan proses mengubah input yang berupa kedalaman tapak ban mobil tangki dan jarak SPBU sehingga mendapatkan output berupa tingkat keselamatan. Kemudian disesuaikan dengan range keanggotaan pada variabel tingkat keselamatan sehingga diperoleh tingkat keselamatan mobil tangki. Dalam penentuan tingkat keselamatan digunakan metode Mamdani atau sering juga dikenal dengan nama Metode Min-Max. Dalam metode ini, pada setiap aturan yang berbentuk implikasi ("sebab-akibat") anteseden yang berbentuk konjungsi (AND) mempunyai nilai keanggotaan berbentuk minimum ( $\mathrm{min}$ ), sedangkan konsekuen gabungannya berbentuk maksimum (max) (Septiawan, 2013).

Tahapan-tahapan untuk membangun logika fuzzy ini meliputi fuzzifikasi, basis pengetahuan, mesin inferensi, dan defuzzifikasi. Dalam fuzzifikasi, data real akan diubah menjadi nilai pendekatan fuzzy melalui fungsi keanggotaan dari masing-masing variabel dalam domain himpunan fuzzy. Himpunan fuzzy kedalaman tapak ban mobil tangki direpresentasikan pada Gambar 2.

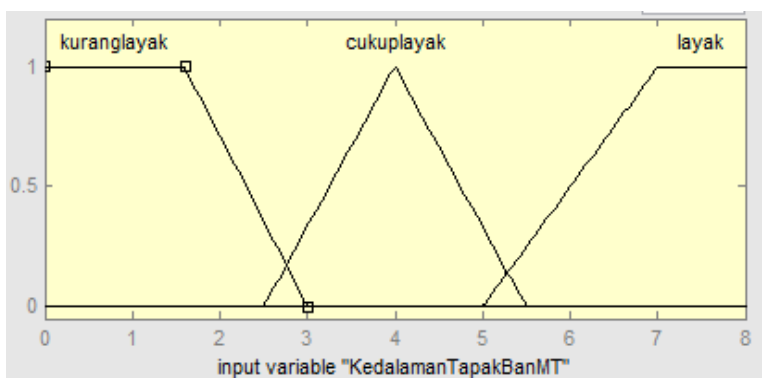

Gambar 2. Himpunan Fuzzy: Kedalaman tapak ban mobil tangki

Variabel input kedalaman tapak ban mobil tangki memiliki tiga kriteria fuzzy, yaitu kurang layak (0 mm-3 mm), cukup layak (2,5 mm - 5,5 $\mathrm{mm}$ ) dan layak (5 mm $-8 \mathrm{~mm})$, dengan fungsi keanggotaan sebagai berikut. 


$$
\begin{aligned}
& \mu \operatorname{KurangLayak}[\mathrm{X}]=1 \\
& (3-x) /(1,4)\left\{\begin{array}{l}
x \leq 1,6 \\
1,6 \leq x \leq 3 \\
x \geq 3
\end{array}\right.
\end{aligned}
$$

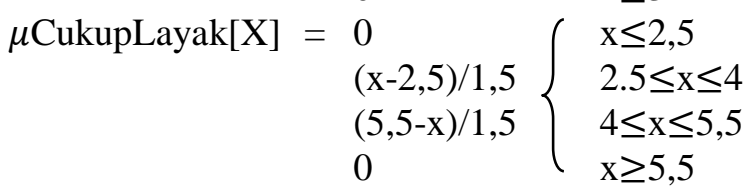

$$
\begin{aligned}
& \mu \text { Layak }[\mathrm{X}] \quad=\begin{array}{l}
0 \\
(\mathrm{x}-5) / 2 \\
1
\end{array} \quad\left\{\begin{array}{l}
\mathrm{x} \leq 5 \\
5 \leq \mathrm{x} \leq 7 \\
7 \leq \mathrm{x} \leq 8
\end{array}\right.
\end{aligned}
$$

Himpunan fuzzy jarak SPBU direpresentasikan pada Gambar 3.

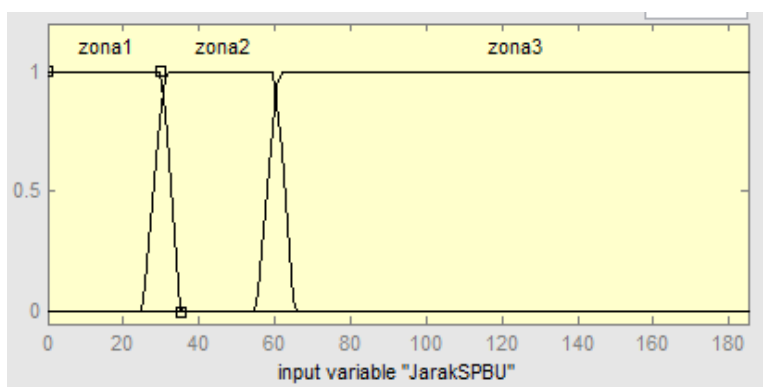

Gambar 3. Himpunan Fuzzy: Jarak SPBU

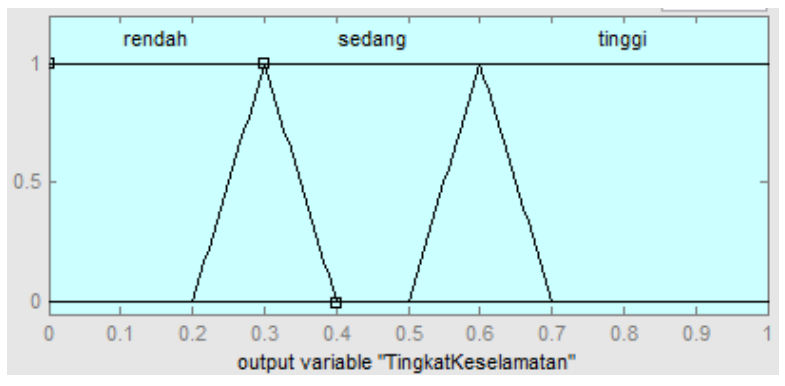

Gambar 4. Himpunan Fuzzy: Tingkat keselamatan mobil tangki

Variabel input jarak SPBU memiliki tiga kriteria fuzzy, yaitu zona $1(0 \mathrm{~km}-35 \mathrm{~km})$, zona $2(25 \mathrm{~km}-65 \mathrm{~km})$ dan zona $3(55 \mathrm{~km}-190 \mathrm{~km})$, dengan fungsi keanggotaan sebagai berikut.

$$
\begin{aligned}
\mu \text { Zona1 }[\mathrm{X}]= & 1 \\
& (35-\mathrm{x}) / 5 \\
& 0 \\
& 0 \\
& (\mathrm{x}-25) / 5 \\
1 & (65-\mathrm{x}) / 5 \\
& 0
\end{aligned} \quad\left\{\begin{array}{l}
\mathrm{x} \leq 30 \\
30 \leq \mathrm{x} \leq 35 \\
\mathrm{x} \geq 35 \\
\mathrm{x} \leq 25 \\
25 \leq \mathrm{x} \leq 30 \\
30 \leq \mathrm{x} \leq 60 \\
60 \leq \mathrm{x} \leq 65 \\
\mathrm{x} \geq 65
\end{array}\right.
$$

$$
\mu \text { Zona3 }[\mathrm{X}]=\begin{aligned}
& 0 \\
& (\mathrm{x}-55) / 5 \\
& 1
\end{aligned} \quad\left\{\begin{array}{l}
\mathrm{x} \leq 55 \\
55 \leq \mathrm{x} \leq 60 \\
60 \leq \mathrm{x} \leq 185
\end{array}\right.
$$

Himpunan fuzzy tingkat keselamatan mobil tangki direpresentasikan pada Gambar 4.

Variabel output tingkat keselamatan mobil tangki memiliki tiga kriteria fuzzy, yaitu rendah $(0-0,4)$, sedang $(0,2-0,7)$ dan tinggi $(0,5-1)$, dengan fungsi keanggotaan sebagai berikut.

$$
\begin{aligned}
& \mu \text { Rendah }[\mathrm{X}]=\begin{array}{l}
1 \\
(0,4-\mathrm{x}) / 0,1 \\
0
\end{array} \quad\left\{\begin{array}{l}
\mathrm{x} \leq 0,3 \\
0,3 \leq \mathrm{x} \leq 0,4 \\
\mathrm{x} \geq 0,4
\end{array}\right.
\end{aligned}
$$

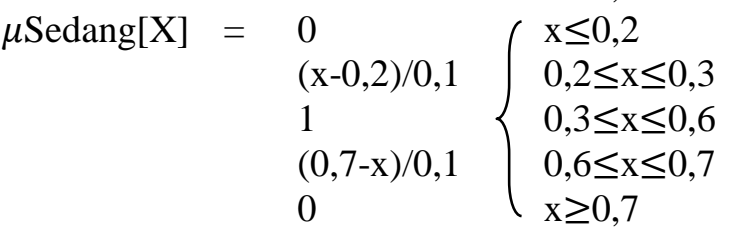

$$
\begin{aligned}
& \mu \text { Tinggi }[\mathrm{X}]=\begin{array}{l}
0 \\
(\mathrm{x}-0,5) / 0,1 \\
1
\end{array} \quad\left\{\begin{array}{l}
\mathrm{x} \leq 0,5 \\
0,5 \leq \mathrm{x} \leq 0,6 \\
0,6 \leq \mathrm{x} \leq 1
\end{array}\right.
\end{aligned}
$$

Proses selanjutnya yaitu pembentukan pengetahuan fuzzy berupa aturan. Aturan-aturan yang dibentuk merupakan suatu implikasi untuk menyatakan relasi antara input dan output. Operator yang digunakan untuk menghubungkan antara dua input adalah operator $A N D$, dan yang memetakan antara input-output adalah IF-THEN. Proposisi yang mengikuti $I F$ disebut anteseden, sedangkan proposisi yang mengikuti THEN disebut konsekuen. Aturan-aturan yang dibentuk seperti pada Gambar 5.

Aturan-aturan yang sudah dibentuk kemudian diproses pada mesin inferensi melalui fungsi implikasi dengan metode mamdani. Pada Metode Mamdani, fungsi implikasi yang digunakan adalah min, yang berarti tingkat keanggotaan yang didapat sebagai konsekuen dari proses ini adalah nilai minimum dari variabel kedalaman tapak ban mobil tangki dan jarak SPBU, sehingga didapatkan daerah fuzzy pada variabel tingkat keselamatan mobil tangki untuk masing-masing aturan. Dilakukan perhitungan dengan memasukkan input pasangan ke-1 dengan kedalaman tapak ban mobil tangki 1,7 mm dan jarak SPBU 0,4 km dengan hasil perhitungan manual seperti pada Gambar 6. 
Pythagoras, 13 (1), 2018 - 29

Wiwiet Widyaningsih, Sri Andayani

Rule Editor: fis2

File Edit View Options

1. If (KedalamanTapakBanMT is kuranglayak) and (JarakSPBU is zona1) then (TingkatKeselamatan is rendah) (1)

2. If (KedalamanTapakBanMT is kuranglayak) and (JarakSPBU is zona2) then (TingkatKeselamatan is rendah) (1)

3. If (KedalamanTapakBanMT is kuranglayak) and (JarakSPBU is zona3) then (TingkatKeselamatan is rendah) (1)

4. If (KedalamanTapakBanMT is cukuplayak) and (JarakSPBU is zona1) then (TingkatKeselamatan is tinggi) (1)

5. If (KedalamanTapakBanMT is cukuplayak) and (JarakSPBU is zona2) then (TingkatKeselamatan is sedang) (1)

6. If (KedalamanTapakBanMT is cukuplayak) and (JarakSPBU is zona3) then (TingkatKeselamatan is sedang) (1)

7. If (KedalamanTapakBanMT is layak) and (JarakSPBU is zona1) then (TingkatKeselamatan is tinggi) (1)

8. If (KedalamanTapakBanMT is layak) and (JarakSPBU is zona2) then (TingkatKeselamatan is tinggi) (1)

9. If (KedalamanTapakBanMT is layak) and (JarakSPBU is zona3) then (TingkatKeselamatan is tinggi) (1)

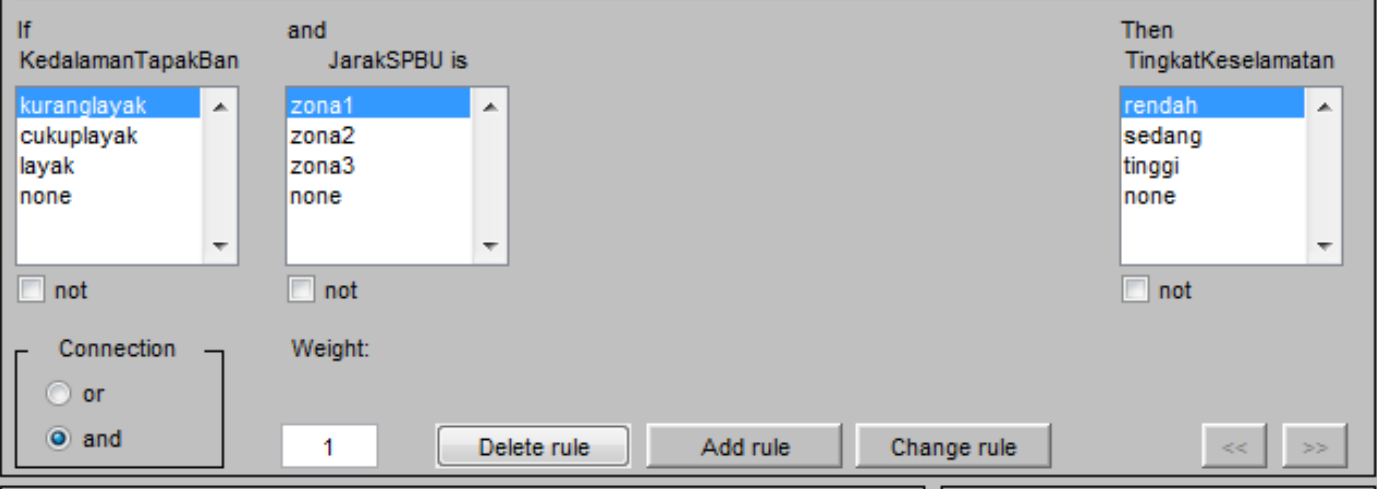

FIS Name: fis2

Gambar 5. Basis Aturan

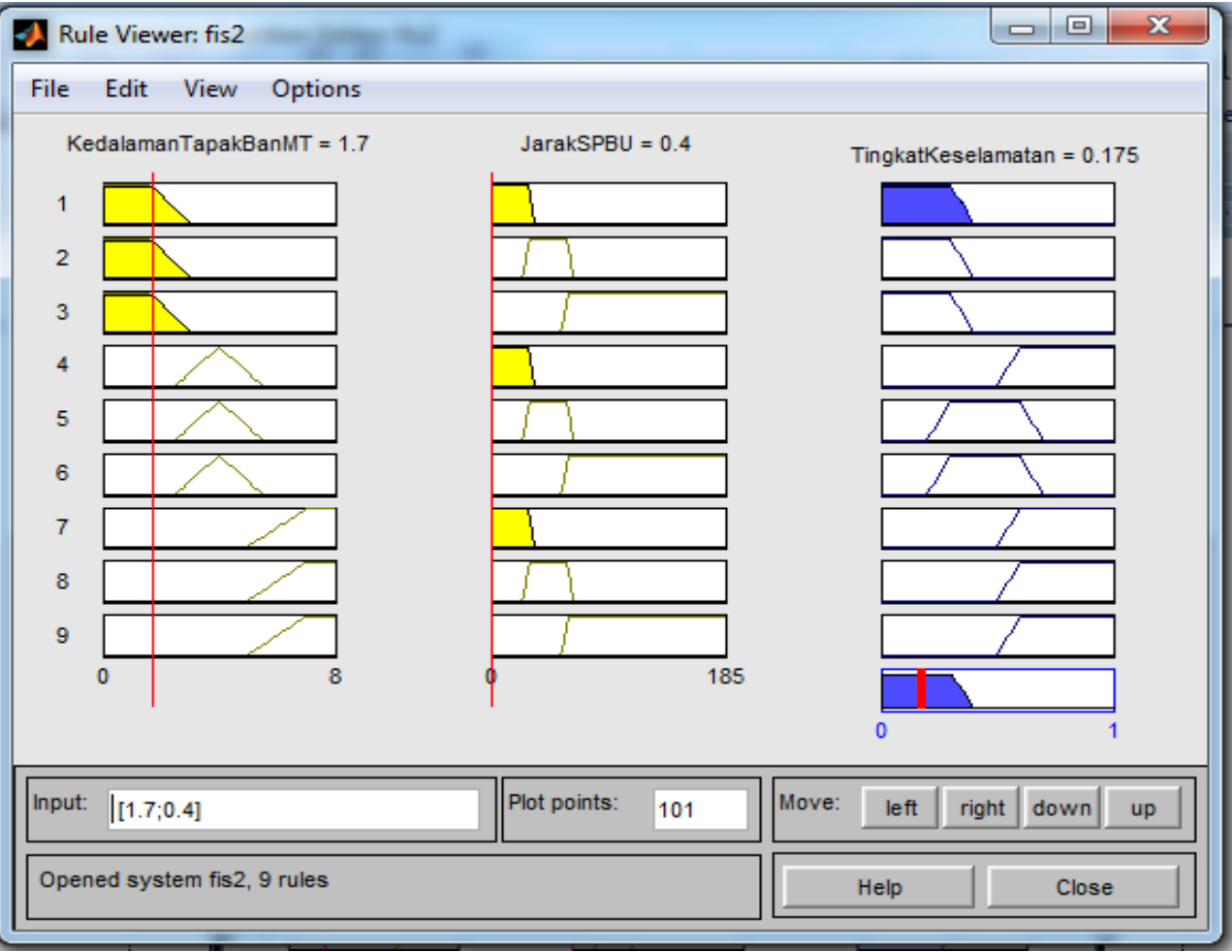

Gambar 6. Mesin Inferensi

$\alpha \_$predikat $1=\mu$ TapakBanKurangLayak $\cap$ $\mu$ JarakZona1

$=\min (\mu$ TapakBanKurangLayak

$(1,7) \cap \mu$ JarakZona1 $(0,4))$

$=\min (0,9285 ; 1)$ 


$$
\mu \text { Tinggi }[\mathrm{X}]=\begin{aligned}
& 0,9285 \\
& (0,4-\mathrm{x}) / 0,1 \\
& 0
\end{aligned} \quad\left\{\begin{array}{l}
\mathrm{x} \leq 0,3071 \\
0,3071 \leq \mathrm{x} \leq 0,4 \\
\mathrm{x} \geq 0,4
\end{array}\right.
$$

Proses selanjutnya adalah defuzzifikasi. Dalam proses defuzzifikasi, metode yang digunakan adalah metode centrodi. Berdasarkan persamaan (9) diperoleh perhitungan sebagai berikut:

$$
\begin{aligned}
& Z_{0}=\frac{\int_{a}^{b} z \cdot \mu_{(Z)} d z}{\int_{a}^{b} \mu_{(Z)} d z} \\
& Z_{0}=\frac{\int_{0}^{0.3071} z \cdot 0.9285 d z+\int_{0.3071}^{0.4} z \cdot \frac{0.4-z}{0.1} d z+\int_{0.4}^{1} z \cdot 0 d}{\int_{0}^{0.3071} 0.9285 d z+\int_{0.3071}^{0.4} \frac{0.4-z}{0.1} d z+\int_{0.4}^{1} 0 d z} \\
& Z_{0}=0,1778035532
\end{aligned}
$$

Dari hasil defuzzifikasi diperoleh nilai centroid $0,1778035532 \approx 0,178$ yang berarti nilai tingkat keselamatan dengan kedalaman tapak ban 1,7 mm dan jarak SPBU 0,4 km adalah 0,178 dan masuk ke dalam zona 1. Dalam penelitian ini, pemrosesan data kendala fuzzy sebanyak 91 pasangan dilakukan dengan menggunakan program MATLAB. Proses dalam tahap mesin inferensi di MATLAB menggunakan metode mamdani, sedangkan dalam tahap defuzzifikasi menggunakan metode centroid.

Hasil output yang didapatkan dari program MATLAB dalam mencari nilai defuzzifikasi untuk tapak ban di zona 1 dengan nilai defuzzifikasi antara 0 sampai 0,3 memiliki rata-rata nilai defuzzifikasi sebesar 0,182115. Pasangan kedalaman tapak mobil tangki dan jarak SPBU tujuan di zona 2 dengan nilai defuzzifikasi antara 0,31 sampai 0,6 memiliki rata-rata nilai defuzzufikasi sebesar 0,47975. Pasangan kedalaman tapak mobil tangki dan jarak SPBU tujuan di zona 3 dengan nilai defuzzifikasi antara 0,31 sampai 0,6 rata-rata nilai defuzzufikasi sebesar 0,770485 .

Formulasi Model Matematika untuk Sasaran

Model matematika goal programming dengan fungsi kendala fuzzy kedalaman tapak ban mobil tangki dan jarak SPBU ini merupakan pengembangan dari goal programming yang sudah dibahas sebelumnya, sehingga sasaran-sasaran yang digunakan merupakan sasaran goal programming yang sudah dibahas sebelumnya pula ditambah satu sasaran dengan kendala fuzzy. Sasaran pertama hingga sasaran keempat memiliki bentuk fungsi kendala dan fungsi tujuan yang sama seperti pada formulasi model sebelumnya, yaitu pada persamaan (1), (2), (3), (4), (5), (6), (7), (8), (9), (10) dan (11).
Sasaran lima yaitu memaksimalkan tingkat keselamatan mobil tangki dalam mendistribusikan BBM. Fungsi kendala untuk sasaran kelima adalah sebagai berikut.

$$
\left(\sum_{j=1}^{4} c_{j k} X_{j}\right)+D B_{i\left(B_{i k}\right)}-D A_{i\left(B_{i k}\right)}=B_{i k}
$$

Dimana $X_{j}=$ jumlah produk $j$ yang diproduksi $(j$ $=1,2,3,4) ; c_{j k}=$ nilai rata-rata defuzzifikasi pasangan kedalaman tapak ban mobil tangki dan jarak SPBU untuk produk $j$ pada zona ke- $k$ ( $k=$ $1,2,3) ; B_{i k}=$ total jumlah permintaan BBM di zona ke- $k$ pada kendala ke- $i(i=1,2, \ldots, m)$; $D B_{i\left(B_{i k}\right)}=$ nilai penyimpangan di bawah $B_{i k}$; $D A_{i\left(B_{i k}\right)}=$ nilai penyimpangan di atas $B_{i k}$. Agar tingkat keselamatan mobil tangki dapat maksimal dalam memenuhi jumlah permintaan BBM di SPBU-SPBU dalam zona tujuan, maka fungsi tujuan $Z_{5}$ menjadi:

$\operatorname{Min} Z_{5}=\sum_{i=1}^{m}\left(D B_{i\left(B_{i k}\right)}+D A_{i\left(B_{i k}\right)}\right)$

Sehingga, model matematika untuk kendala dalam memaksimalkan tingkat keselamatan mobil tangki dalam mendistribusikan BBM ke SPBUSPBU tujuan dalam zona 1 , zona 2 dan zona 3 berturut-turut adalah sebagai berikut.

$$
\begin{aligned}
& 0,182115 X_{1}+0,182115 X_{2}+0,182115 X_{3} \\
& +0,182115 X_{4}+D B_{8}-D A_{8}=1820 \\
& 0.47975 X_{1}+0.47975 X_{2}+0.47975 X_{3} \\
& 0.47975 X_{4}+D B_{9}-D A_{9}=1552 \\
& 0,770485 X_{1}+0,770485 X_{2}+0,770485 X_{3} \\
& +0,770485 X_{4}+D B_{10}-D A_{10}=1072
\end{aligned}
$$

Dengan nilai ruas kanan merupakan total jumlah permintaan BBM di SPBU-SPBU dalam zona tujuan dan nilai koefisien pada setiap variabel di ruas kiri adalah nilai rata-rata defuzzifikasi untuk zona ke- $n$. Adapun fungsi tujuannya yaitu:

$$
\begin{aligned}
& M i n \\
& D A_{10}
\end{aligned}=D B_{8}+D A_{8}+D B_{9}+D A_{9}+D B_{10}+
$$

Penyelesaian Optimasi Menggunakan Program LINGO

Penyelesaian optimasi dilakukan menggunakan program LINGO dengan memasukkan script input berupa fungsi tujuan dan fungsi kendala yang sudah dibentuk kemudian menggunakan perintah "Solve" untuk mengoptimasikannya. Hasil optimasi yang dilakukan dengan program LINGO untuk metode goal programming dengan fungsi kendala fuzzy dapat dilihat pada Tabel 3 . 
Pythagoras, 13 (1), 2018 - 31

Wiwiet Widyaningsih, Sri Andayani

Tabel 3. Hasil optimasi goal programming dengan fungsi kendala fuzzy menggunakan program LINGO

\begin{tabular}{|c|c|c|c|c|c|c|}
\hline \multirow{5}{*}{$\begin{array}{ll}\text { No. } \\
1 .\end{array}$} & \multirow{5}{*}{\begin{tabular}{l}
\multicolumn{1}{c}{ Kendala } \\
Memaksimalkan volume produksi untuk \\
memenuhi jumlah permintaan
\end{tabular}} & \multicolumn{2}{|c|}{ Sasaran } & \multirow{2}{*}{$\begin{array}{c}D A \\
0\end{array}$} & \multirow{2}{*}{$\begin{array}{c}\boldsymbol{D B} \\
0\end{array}$} & \multirow{2}{*}{$\begin{array}{r}\text { Hasil } \\
1016\end{array}$} \\
\hline & & $X_{1}$ & 1016 & & & \\
\hline & & $X_{2}$ & 1200 & 0 & 0 & 1200 \\
\hline & & $X_{3}$ & 596 & 0 & 0 & 596 \\
\hline & & & 1632 & 0 & 0 & 1632 \\
\hline 2. & Memaksimalkan pendapatan penjualan & \multicolumn{2}{|c|}{$F$} & 0 & 0 & 33022000000 \\
\hline 3. & $\begin{array}{l}\text { Memaksimalkan jam kerja mesin pengisian } \\
\text { BBM di NGS }\end{array}$ & \multicolumn{2}{|c|}{10080} & 9405,556 & 0 & 674,444 \\
\hline 4. & Memaksimalkan moda transport mobil tangki & \multicolumn{2}{|c|}{2144} & 0 & 2300 & 4444 \\
\hline \multirow[t]{3}{*}{5.} & $\begin{array}{l}\text { Memaksimalkan tingkat keselamatan mobil } \\
\text { tangki dalam mendistribusikan BBM }\end{array}$ & $\begin{array}{c}\text { Zona } \\
1\end{array}$ & 1820 & 1010,681 & 0 & 809,319 \\
\hline & & $\begin{array}{l}\text { Zona } \\
2\end{array}$ & 1552 & 0 & 580,009 & 2132,009 \\
\hline & & $\begin{array}{l}\text { Zona } \\
3\end{array}$ & 1072 & 0 & 2352,035 & 3424,035 \\
\hline
\end{tabular}

Berdasarkan hasil optimasi goal programming dengan fungsi kendala fuzzy menggunakan program LINGO pada Tabel 3, didapat hasil intepretasi. Sasaran pertama hingga sasaran keempat memiliki hasil output yang sama seperti pada perhitungan goal programming sebelumnya. Sasaran memaksimalkan tingkat keselamatan mobil tangki dalam mendistribusikan BBM tercapai untuk mobil tangki di zona 2 dan zona 3 . Di zona 2 , sasaran yang diinginkan adalah mobil tangki di zona 2 dapat mendistribusikan BBM sebanyak $1552 \mathrm{kl}$ sesuai permintaan. Didapat nila $D A$ sebesar 580,009 yang berarti mobil tangki di zona 2 dengan nilai tingkat keselamatan sebesar 0,47975 dapat mendistribusikan BBM total sebanyak 2132,009 kl dengan nilai tingkat keselamatan konsisten di 0,47975, dan hal tersebut merupakan pencapaian yang bagus. Di zona 3, sasaran yang diinginkan adalah mobil tangki di zona 3 dapat mendistribusikan BBM sebanyak $1072 \mathrm{kl}$ sesuai permintaan. Didapat nila $D A$ sebesar 2352,035 yang berarti mobil tangki di zona 3 dengan nilai tingkat keselamatan sebesar 0,770485 dapat mendistribusikan BBM total sebanyak 3424,035 kl dengan nilai tingkat keselamatan konsisten di 0,770485 , dan hal tersebut merupakan pencapaian yang bagus. Namun untuk mobil tangki di zona 1 tidak memenuhi sasaran. Sasaran yang diinginkan adalah mobil tangki di zona 1 dapat mndistribusikan BBM sebanyak $1820 \mathrm{kl}$, namun didapat nilai $D B$ sebesar 1010,681 yang berarti mobil tangki di zona 1 dengan nilai tingkat keselamatan sebesar 0,182115 hanya dapat mendistribusikan BBM total sebanyak 809,319 $\mathrm{kl}$ dengan nilai tingkat keselamatan konsisten di 0,182115. Selebihnya dalam mendistribusikan BBM mobil tangki di zona 1 tidak dapat memiliki nilai tingkat keselamatan 0,182115 , hal ini dikarenakan tapak ban mobil tangki sudah semakin mendekati ukuran kedalaman 0,16 mm dengan nilai tingkat keselamatan yang rendah walaupun hanya untuk mendistribusika BBM ke SPBU dengan jarak dekat $30 \mathrm{~km}$ kebawah, sehingga ban mobil tangki harus segera diganti dengan ban baru.

\section{Pembahasan}

Solusi goal programming dengan fungsi kendala biasa dan fungsi kendala fuzzy dengan sasaran memaksimalkan volume produksi untuk memenuhi jumlah permintaan telah memberikan hasil yang sesuai dengan tujuan yang ditetapkan, yakni memenuhi jumlah permintaan dengan jumlah pendapatan yang maksimal. Selain itu, jumlah pendapatan maksimal dapat juga dicari dengan mencoba memberikan nilai-nilai yang berbeda untuk permintaan setiap jenis BBM. Untuk itu, dilakukan perhitungan yang melibatkan berbagai kombinasi susunan jumlah permintaan setiap jenis produk BBM untuk mengetahui apakah terdapat solusi nilai pendapatan $(F)$ yang lebih maksimal dibandingkan dengan solusi nilai $F$ pada goal programming dengan fungsi kendala biasa dan fungsi kendala fuzzy sebelumnya.

Kombinasi susunan jumlah permintaan setiap jenis produk BBM dicari menggunakan rumus permutasi, karena permutasi memperhatikan urutan susunan anggota sedangkan kombinasi tidak memperhatikan urutan susunan anggota, maka rumus permutasinya adalah sebagai berikut (Soedyarto \& Maryanto, 2008).

$$
P(n, n)=n !=4 !=4 \times 3 \times 2 \times 1=24
$$


Dengan demikian, banyaknya susunan dari jenis produk BBM dan jumlah permintaannya adalah sebanyak 24 macam. Hasil optimasi goal programming dari 24 macam susunan tersebut dengan fungsi kendala biasa dan fungsi kendala fuzzy menunjukkan bahwa pendapatan tertinggi sebesar Rp34.154.400.000,00 dapat diperoleh jika permintaan produk premium sebanyak 596 $\mathrm{kl}$, bio solar sebanyak $1016 \mathrm{kl}$, pertamax sebesar $1632 \mathrm{kl}$, dan pertalite sebesar $1200 \mathrm{kl}$.

Dengan demikian dapat disarankan untuk PT. Pertamina (Persero) TBBM Boyolali untuk dapat memproduksi BBM dengan produk premium sebanyak $596 \mathrm{kl}$, bio solar sebanyak 1016 $\mathrm{kl}$, pertamax sebesar $1632 \mathrm{kl}$, dan pertalite sebesar 1200 kl. Untuk itu, PT. Pertamina (Persero) TBBM Boyolali perlu membuat promosi atau usaha apapun yang dapat membuat SPBU-SPBU untuk memesan BBM dengan jumlah tersebut, karena PT. Pertamina (Persero) TBBM Boyolali tidak dapat mengatur pasar atau mengatur banyaknya jumlah permintaan BBM yang akan dijual ke SPBU-SPBU.

\section{SIMPULAN}

Kesimpulan yang dapat diambil dari rumusan masalah dan hasil penelitian adalah penyelesaian optimasi model matematika pada perencanaan produksi BBM dengan fungsi kendala biasa dan fungsi kendala fuzzy dengan metode goal programming menggunakan program LINGO menghasilkan output jumlah BBM dan jumlah pendapatan yang sama, yaitu jumlah produk premium $\left(X_{1}\right)$ sebanyak $1016 \mathrm{kl}$, bio solar $\left(X_{2}\right)$ sebanyak $1200 \mathrm{kl}$, pertamax $\left(X_{3}\right)$ sebanyak $596 \mathrm{kl}$, dan pertalite $\left(X_{1}\right)$ sebanyak $1632 \mathrm{kl}$ dengan pendapatan sebesar Rp33.022.000.000, 00 .

Berdasarkan hasil penelitian tersebut maka saran untuk penelitian selanjutnya adalah perlunya menambahkan faktor lain yang dapat mempengaruhi kendala fuzzy tingkat keselamatan mobil tangki selain kedalaman tapak ban mobil tangki dan jarak SPBU, atau mencari kendala fuzzy yang lain. Dalam sasaran memaksimalkan jam kerja mesin pengisian BBM di NGS perlu memperhatikan faktor-faktor lain selain jam kerja mesin pengisian, yaitu faktor-faktor dalam kegiatan operasional yang justru membutuhkan waktu yang lebih lama, seperti memarkirkan mobil ke dalam bay di filling point untuk melakukan pengisian, memasang arm, mengatur komputer mesin untuk mengisikan BBM sesuai dengan permintaan, membuka dan menutup kompartemen mobil tangki, mengeluarkan mobil dari bay dan lain-lain. Hal ini bertujuan agar faktorfaktor lain juga dapat memberikan kontribusi dalam memaksimalkan jam kerja mesin pengisian BBM di NGS.

\section{DAFTAR PUSTAKA}

Baroto, T. (2002). Perencanaan dan pengendalian produksi. Jakarta: UI Press.

Charles, D., \& Simpson, T. (2002). Goal programming application in multidisciplinary design optimazation. Retrieved from http://www.dtic.mil/ndia/2001sbac /simpson

Kusumadewi, W., \& Idham, G. (2005). Fuzzy multi-criteria decision making. Media Informatika, 3(1), 25-38.

Lestari, D., Ratna, E., \& Rosita K. (2012). Optimasi Persediaan Bahan Bakar Minyak (BBM) di Yogyakarta Menggunakan Goal Programming. Laporan Penelitian Dosen Yunior Anggota PUSDI Tahun Anggaran 2012. Yogyakarta: LPPM UNY.

Septiawan, R. A. (2013). Implementasi logika fuzzy Mamdani untuk menentukan harga gabah. Retrieved from http://mahasiswa. dinus.ac.id/docs/skripsi/jurnal/12328.pdf

Setiaji. (2009). Himpunan dan logika samar serta aplikasinya. Yogyakarta: Graha Ilmu.

Siswanto. (2007). Operations research jilid 1. Jakarta: Erlangga.

Soedyarto, N., \& Maryanto. (2008). Matematika untuk SMA dan MA kelas XI program IPA jilid 2. Jakarta: Pusat Perbukuan Departemen Pendidikan Nasional.

Soekartawi. (1992). Linier programming. Jakarta: Erlangga.

TBBM Boyolali terapkan new gantry system. (2017). Retrieved from www.pertamina. com/news-room/seputar-energi/tbbmboyolali-terapkan-new-gantry-system. 